\section{International Mobile Satellite Organization (IMSO)}

Founded in 1979 as the International Maritime Satellite Organization (Inmarsat) to establish a satellite system to improve maritime communications for distress and safety and commercial applications. Its competence was subsequently expanded to include aeronautical and land mobile communications. Privatization, which was completed in April 1999, transferred the business to a newly created company and the Organization remains as a regulator to ensure that the company fulfils its public services obligations. The company has taken the Inmarsat name and the Organization uses the acronym IMSO. In Feb. 2012 the Organization had 97 member parties.

Organization. The Assembly of all Parties to the Convention meets every two years.

Headquarters: 99 City Road, London EC1Y 1AX, UK.

IMSO Website: http://www.imso.org

Email: info@imso.org

Inmarsat Website: http://www.inmarsat.com

Director of the Secretariat, IMSO: Esteban Pachá Vicente (Spain).

Chief Executive, Inmarsat Ltd: Andrew Sukawaty (USA).

\section{International Olympic Committee (IOC)}

Founded in 1894 by French educator Baron Pierre de Coubertin, the International Olympic Committee is an international nongovernmental, non-profit organization whose members act as the IOC's representatives in their respective countries, not as delegates of their countries within the IOC. The Committee's main responsibility is to supervise the organization of the summer and winter Olympic Games. It owns all rights to the Olympic symbols, flag, motto, anthem and Olympic Games.

Aims. 'To contribute to building a peaceful and better world by educating youth through sport, practised without discrimination of any kind and in the Olympic Spirit, which requires mutual understanding with a spirit of friendship, solidarity and fair play.'

Finances. The IOC receives no public funding. Its only source of funding is from private sectors, with the substantial part of these revenues coming from television broadcasters and sponsors.

Address: Château de Vidy, Case Postale 356, CH-1007

Lausanne, Switzerland.

Website: http://www.olympic.org

President: Jacques Rogge (Belgium).

\section{International Organisation of La Francophonie}

The International Organisation of La Francophonie represents 70 countries and provinces/regions (including 14 with observer status) using French as an official language. It estimates that there are $220 \mathrm{~m}$. French speakers worldwide. Objectives include the promotion of peace, democracy, and economic and social development, through political and technical co-operation. The Secretary-General is based in Paris.
Members. Albania, Andorra, Belgium, Benin, Bulgaria, Burkina Faso, Burundi, Cambodia, Cameroon, Canada, Canada-New Brunswick, Canada-Quebec, Cape Verde, Central African Republic, Chad, Comoros, Democratic Republic of the Congo, Republic of the Congo, Côte d'Ivoire, Djibouti, Dominica, Egypt, Equatorial Guinea, France, French Community of Belgium, Gabon, Greece, Guinea, Guinea-Bissau, Haiti, Laos, Lebanon, Luxembourg, Macedonia, Madagascar, Mali, Mauritania, Mauritius, Moldova, Monaco, Morocco, Niger, Romania, Rwanda, St Lucia, São Tomé e Príncipe, Senegal, Seychelles, Switzerland, Togo, Tunisia, Vanuatu, Vietnam. Associate Members. Armenia, Cyprus, Ghana. Observers. Austria, Bosnia and Herzegovina, Croatia, Czech Republic, Dominican Republic, Estonia, Georgia, Hungary, Latvia, Lithuania, Montenegro, Mozambique, Poland, Serbia, Slovakia, Slovenia, Thailand, Ukraine, United Arab Emirates.

Headquarters: 19-21 avenue Bosquet, 75326 Paris, France.

Website (limited English): http://www.francophonie.org

Secretary-General: Abdou Diouf (Senegal).

\section{International Organization for Migration (IOM)}

Established in 1951, the International Organization for Migration (IOM) is the principal intergovernmental organization in the field of migration.

Members (146 as of Feb. 2012). Afghanistan, Albania, Algeria, Angola, Antigua and Barbuda, Argentina, Armenia, Australia, Austria, Azerbaijan, Bahamas, Bangladesh, Belarus, Belgium, Belize, Benin, Bolivia, Bosnia and Herzegovina, Botswana, Brazil, Bulgaria, Burkina Faso, Burundi, Cambodia, Cameroon, Canada, Cape Verde, Central African Republic, Chad, Chile, Colombia, Comoros, Democratic Republic of the Congo, Republic of the Congo, Costa Rica, Côte d'Ivoire, Croatia, Cyprus, Czech Republic, Denmark, Djibouti, Dominican Republic, Ecuador, Egypt, El Salvador, Estonia, Ethiopia, Finland, France, Gabon, Gambia, Georgia, Germany, Ghana, Greece, Guatemala, Guinea, Guinea-Bissau, Guyana, Haiti, Holy See, Honduras, Hungary, India, Iran, Ireland, Israel, Italy, Jamaica, Japan, Jordan, Kazakhstan, Kenya, South Korea, Kyrgyzstan, Latvia, Lesotho, Liberia, Libya, Lithuania, Luxembourg, Madagascar, Maldives, Mali, Malta, Mauritania, Mauritius, Mexico, Micronesia, Moldova, Mongolia, Montenegro, Morocco, Mozambique, Namibia, Nauru, Nepal, Netherlands, New Zealand, Nicaragua, Niger, Nigeria, Norway, Pakistan, Panama, Paraguay, Peru, Philippines, Poland, Portugal, Romania, Rwanda, Senegal, Serbia, Seychelles, Sierra Leone, Slovakia, Slovenia, Somalia, South Africa, South Sudan, Spain, Sri Lanka, Sudan, Swaziland, Sweden, Switzerland, Tajikistan, United Republic of Tanzania, Thailand, Timor-Leste, Togo, Trinidad and Tobago, Tunisia, Turkey, Uganda, Ukraine, UK, USA, Uruguay, Vanuatu, Venezuela, Vietnam, Yemen, Zambia and Zimbabwe. A further 13 countries have observer status.

Activities. IOM works to help ensure the orderly and humane management of migration, to promote international co-operation on migration issues, to assist in the search for practical solutions to migration problems and to provide humanitarian assistance to migrants in need, be they refugees, displaced persons or other uprooted people. The IOM Constitution gives explicit recognition to the link between migration and economic, social and cultural development, as well as to the right of freedom of movement of persons. IOM works in the four broad areas of migration management: migration and development, facilitating migration, regulating migration and addressing forced migration. IOM's programme budget for 2010 exceeded US $\$ 1 \mathrm{bn}$., funding over 